\title{
Avaliação do material particulado no ar atmosférico em área de influência de usina termelétrica considerando as diferentes tecnologias adotadas no controle de efluentes atmosféricos
}

\begin{abstract}
Rita Clarice Machado Tissot ${ }^{1,3 *}$ Marçal José Rodrigues Pires ${ }^{2}$ Rita de Cássia Marques Alves ${ }^{1}$ Renato S. Barbosa
\end{abstract}

${ }^{1}$ Universidade Federal do Rio Grande do Sul Instituto de Geociências

${ }^{2}$ Pontifícia Universidade Católica do Rio Grande do Sul

Faculdade de Química

${ }^{3}$ ENGIE Brasil Energia S.A.

Usina Termelétrica do Rio Grande do Sul Endereço Rua Geólogo White $s / n^{\circ}$ Centro CEP 96745000 - Charqueadas - RS

ritactissot@gmail.com mpires@pucrs.br rita.cma@terra.com.br renato.barbosa@engie.com

* Autora para correspondência

\begin{abstract}
Resumo
O objetivo deste trabalho foi verificar a qualidade do ar no município de Charqueadas, localizado na Região Metropolitana de Porto Alegre, através dos dados de rotina de duas estações de monitoramento ambiental operadas pela Tractebel Energia, uma na cidade de Charqueadas e outra no município de Triunfo. Os resultados de partículas totais em suspensão (PTS) e partículas inaláveis (PM10) foram comparados com a Resolução CONAMA 03/1990 e a partir de amostras de material particulado total, foram realizadas análises de espectroscopia atômica e espectroscopia dispersiva de raio -X para identificar os elementos presentes no ar ambiente e sua relação com as principais fontes de emissão da região. As análises mostraram que a qualidade do ar observada na Estação localizada em Triunfo é melhor do que a observada na Estação de Charqueadas. Os dados obtidos indicam que há um reflexo positivo na qualidade do ar relacionado a implantação das tecnologias que reduziram as emissões de poluentes para a atmosfera. A análise das amostras revelou a presença de partículas de origem natural e antropogênica, entre os elementos analisados, os de maior concentração foram $\mathrm{Fe}$ e $\mathrm{Mn}$ nos dois locais avaliados, embora outros elementos químicos característicos de áreas urbanas industriais também tenham sido identificados. Com relação a caracterização morfológica das partículas de PTS as imagens obtidas mostram a presença de partículas heterogêneas com diferentes formas e tamanhos, os elementos predominantes foram o silício e o alumínio, no caso do silício está presente na composição dos filtros de fibra de vidro utilizados na amostragem.
\end{abstract}

Palavras-chave: Poluição do Ar, material particulado, morfologia, termelétrica, carvão

\section{Abstract}

The aim of this study was to assess the air quality in the city of Charqueadas, located in the metropolitan area of Porto Alegre, through routine data from two environmental monitoring stations operated by Tractebel Energia, one in the city of Charqueadas and another in the city of Triunfo. The results of Total suspended particulate matter (TSP) and respirable particulate matter (PM10) were compared with CONAMA Resolution 03/1990 and from total particulate matter samples, analyzes were carried out from atomic spectroscopy and dispersive spectroscopy -X-ray to identify the elements present in ambient air and its relation to the main sources of emissions in the region. The analysis showed that the air quality observed in located in Triunfo station is better than that observed in Charqueadas Station. The data indicate that there is a positive impact on air quality related to deployment of technologies that have reduced emissions of pollutants into the atmosphere. The analysis of the samples revealed the presence of particles from natural and anthropogenic sources, among the analyzed elements, Fe and $\mathrm{Mn}$ was 
found higher concentration at to two sites evaluated, although other characteristic of industrial chemicals urban areas have also been identified. Regarding morphological characterization of PTS particles obtained images showed the presence of heterogeneous particles with different shapes and sizes, the predominant elements are silicon and aluminum, if the silicon is present in the composition of the glass fiber filters used in sampling.

Keywords: Air Pollution, particulate material, morphology, thermal, coal power plant

\section{INTRODUÇÃO}

Os grandes centros urbanos enfrentam vários problemas relacionados à poluição atmosférica. Os efeitos na saúde ocasionados pela alta concentração dos poluentes têm sido objeto de alerta da Organização Mundial da Saúde (WHO, 2015) que recentemente emitiu um relatório mundial sobre a qualidade do ar urbano com dados preocupantes em especial das partículas inaláveis.

As partículas na atmosfera podem ter origem antropogênica como as emitidas em processos industriais, queima de combustíveis fósseis, queima de biomassa entre outros, enquanto que as partículas de origem naturais estão relacionadas a uma variedade de processos que incluem as emissões vulcânicas, o transporte pelo vento de partículas oriundas da crosta terrestre e dos oceanos. As fontes de emissão, as reações atmosféricas e as condições meteorológicas, são fatores determinantes no tamanho e composição do material particulado. Os compostos que compõe as partículas em suspensão podem ser de origem orgânica (carbono orgânico e elementar, compostos voláteis e semivoláteis absorvido inorgânica (sulfatos, nitratos, amônio, cloretos e elementos traço) e biológica (bactérias, esporos e polens) (Seinfeld e Pandis, 2006).

A princípio, os estudos de material particulado basearam-se nas concentrações de particulados totais em suspensão (PTS). Nas últimas décadas, as agências de proteção ambiental de vários países, incluindo Canadá e Estados Unidos, adotaram a utilização do monitoramento do material particulado MP10, cujo resultado é a concentração de todas as partículas com diâmetros menores do que $10 \mu \mathrm{m}$, que são as partículas inaláveis. Posteriormente, iniciou o monitoramento para o MP 2,5 que inclui todas as partículas finas, respiráveis. Essas partículas podem penetrar mais profundamente no sistema respiratório e possuem um potencial maior de danos à saúde.
Mais recentemente, um novo termo, ultrafino, passou a ser utilizado para indicar o monitoramento de partículas menores do que $0,1 \mu \mathrm{m}$; a maioria das partículas ultrafinas são de origem antropogênica. (Baird, 2011)

A Região Metropolitana de Porto Alegre (RMPA), área onde está inserido o município de Charqueadas, é a área de maior densidade populacional e industrial do Estado do Rio Grande do Sul, razão pela qual é mais afetada pela concentração de poluentes atmosféricos. No centro do município de Charqueadas, distante $50 \mathrm{~km}$ de Porto Alegre, situa-se a Usina Termelétrica de Charqueadas (UTCH), movida a carvão fóssil e em operação comercial desde o ano de 1962. Entre os poluentes lançados por uma central térmica a carvão, destacam-se, pelo impacto local ou regional, o material particulado, os óxidos de nitrogênio (NOx) e os óxidos de enxofre (SOx). (JICA, 1997; Pires et al., 2002). A combustão do carvão é também uma fonte potencial de elementos traço para a atmosfera incluindo metais tóxicos. A preocupação sobre os efeitos dos poluentes traço no ambiente levou à introdução de normas de emissão para alguns destes elementos (IEA, 2012). Na tabela 1 são mostrados os elementos traço considerados de interesse ambiental segundo o US National Research Council (IEA, 2012) com base nos efeitos adversos para a saúde.

Dispositivos de controle de particulados convencionais, tais como precipitadores ou filtros de manga são eficazes na captura geral dos elementos na corrente do particulado como $\mathrm{As}, \mathrm{Cd}, \mathrm{Cr}, \mathrm{Ni}$ e $\mathrm{Pb}$. Uma combinação de tecnologia de controle de partículas e FGD (Flue Gas Desulfurization) pode auxiliar na captura de outros elementos menores. Contudo, alguns elementos incluindo $\mathrm{Hg}, \mathrm{Cl}, \mathrm{Se}, \mathrm{B}$ não são consistentemente capturados pelo controle de poluentes atmosféricos convencionais existentes. 
Tabela: 1- Classificação dos elementos traço e a preocupação ambiental em carvão.

\begin{tabular}{ll}
\hline Classificação & Elemento \\
\hline Grande preocupação & $\mathrm{As}, \mathrm{B}, \mathrm{Cd}, \mathrm{Pb}, \mathrm{Hg}, \mathrm{Mo}$ e $\mathrm{Se}$. \\
Preocupação Moderada & $\mathrm{Cr}, \mathrm{V}, \mathrm{Cu}, \mathrm{Zn}, \mathrm{Ni}$ e F. \\
$\begin{array}{l}\text { Menor preocupação } \\
\text { Elementos de preocupação, mas com } \\
\text { concentrações insignificantes }\end{array}$ & $\mathrm{Be}, \mathrm{Ta}, \mathrm{Ng}, \mathrm{Mn}, \mathrm{Co}, \mathrm{Sb}, \mathrm{Li}, \mathrm{Cl}, \mathrm{Br}$ e $\mathrm{Ge}$. \\
Elementos radioativos & $\mathrm{U}$ e Th \\
\hline
\end{tabular}

Este trabalho tem como objetivo avaliar os resultados do monitoramento de longo prazo de PTS (1995 a 2015) e PM10 (2010-2015), e a influência das melhorias no controle das emissões atmosféricas da usina termelétrica UTCH, na qualidade do ar na cidade de Charqueadas. A identificação da

\section{AREA DE ESTUDO}

O município de Charqueadas possui uma área de territorial de $216,51 \mathrm{~km}^{2}$ e uma população de cerca de 36.000 habitantes (IBGE, 2013). Situa-se na configuração topográfica da Depressão Central do estado do Rio Grande do Sul apresentando uma altitude média de 20 metros ao nível do mar. A cidade de Charqueadas faz parte da microrregião carbonífera situada na porção oriental do Baixo Jacuí. O clima da bacia do Baixo Jacuí é do tipo mesotérmico, conforme a classificação de Köppen, caracterizada por temperaturas compreendidas entre -3 e $18^{\circ} \mathrm{C}$ no mês mais frio e superior a $22^{\circ} \mathrm{C}$ no mês mais quente, quanto a precipitação possui totais anuais superiores a $1.200 \mathrm{~mm}$ bem distribuídos ao longo do ano. Os ventos predominantes são de Sudeste, com maior intensidade nos meses de primavera e a umidade relativa do ar é alta o ano inteiro, sempre maior que $70 \%$, em função do alto teor de umidade das massas atuantes (Ferraro et al. 2000)

A economia do município de Charqueadas onde este estudo foi realizado, é predominantemente industrial. Além da termelétrica (TRACTEBEL ENERGIA) e da siderúrgica (GERDAU) que impulsionaram o crescimento industrial de Charqueadas, outras empresas fazem parte do parque industrial da cidade como COPELMI - que possui um entreposto de armazenamento e manuseio de carvão, GKN - fabricante de juntas homocinéticas, METASA - fabricação e composição química e da morfologia do PTS também foi realizada. Os resultados são comparados com as legislações vigentes e com elementos químicos específicos que indiquem a utilização do carvão em processo de queima e possam ser utilizados como traçador dessa utilização em análise de qualidade do ar.

montagem no ramo de estruturas metálicas e outras indústrias de menor porte.

O município recebeu o projeto, de origem alemã, da Usina termelétrica na década de 1950. Os filtros originais para a captação das cinzas resultantes da combustão eram mecânicos (ciclones), com capacidade para captar entre 40 e $60 \%$ das cinzas leves produzidas. A usina de Charqueadas funcionou com esse controle pouco eficiente, desde a sua partida em 1962 até dezembro 1987 (JICA, 1997). Em 1974 entrou em operação a Siderúrgica Aços Finos Piratini, impactando ainda mais a qualidade do ar devido as emissões lançadas sem controle para a atmosfera. As melhorias no controle de emissão de poluentes na termelétrica iniciaram no ano de 1987, quando foram instalados na Usina Termelétrica os precipitadores eletrostáticos com eficiência de $98,99 \%$, essa mudança trouxe reflexos positivos para a melhoria da qualidade do ar na região. A partir de 2009 foram instalados os filtros de mangas, o que aumentou a eficiência do despoeiramento para $99,9 \%$ e instalado o lavador de gases FGD (Flue Gas Desulfurization) com eficiência de $90 \%$ na remoção dos gases de enxofre. A instalação desses equipamentos foi para atingir os seguintes limites de emissão de poluentes corrigidos a $6 \%$ de oxigênio: $\mathrm{SO}_{2} \quad 400$ $\mathrm{mg} / \mathrm{Nm}^{3}$, NOx $550 \mathrm{mg} / \mathrm{Nm}^{3}$ e Material particulado $80 \mathrm{mg} / \mathrm{Nm}^{3}$. Com a nova tecnologia a redução de poluentes na fonte de 
emissão foi da ordem de 10 vezes na emissão de dióxido de enxofre e em torno de 4 vezes na emissão de material particulado. Outro fato importante para a qualidade do ar na região é a

\section{MATERIAIS E MÉTODOS}

Os dados de monitoramento utilizados neste estudo foram obtidos das estações de monitoramento de qualidade do ar operadas pela Tractebel Energia. Os pontos de coleta estão localizados em dois municípios distintos, uma das estações (AT - Arranca Toco) encontra-se instalada a cerca de $700 \mathrm{~m}$ à jusante do vento predominante (SE), em relação à usina e próximo ao centro urbano de

\subsection{MÉTODOS DE AMOSTRAGEM}

As amostras de TSP foram coletadas conforme os procedimentos previstos na norma ABNT - NBR No 9547/1998 através de amostrador de ar de grandes volumes denominado Hi-vol, fabricado pela Sierra Andersen. Foram avaliadas as amostras coletadas na Estação Arranca Toco e DEPREC considerando dados obtidos na série temporal de 20 anos no período de 1996 a 2015. A estatística descritiva dessa série de dados foi utilizada como forma de fazer uma avaliação exploratória desses dados.

Para avaliar a composição química detalhada, os filtros de TSP disponibilizados foram os filtros amostrados a partir de 2009 até 2015. Foram analisados 22 filtros da Estação Arranca Toco e 18 da Estação DEPREC. Os elementos escolhidos para análise basearam-se na classificação do NRC-US (Tabela 1): Li, $\mathrm{Be}, \mathrm{V}, \mathrm{Cr}, \mathrm{Mn}, \mathrm{Fe}, \mathrm{Ni}, \mathrm{Co}, \mathrm{Cu}, \mathrm{Se}, \mathrm{Mo}, \mathrm{Ag}$, $\mathrm{Cd}, \mathrm{Ti}, \mathrm{Pb}, \mathrm{U}$. A concentração de TSP obtida em cada amostragem, a geração em MW e os

\subsection{TÉCNICAS ANALÍTICAS}

Após selecionados os filtros foram analisados por ICP-MS (Agilent modelo 7700). Para uma mesma amostra, o filtro foi cortado em oitavos, e $2 / 8$ foram pesados $(0,35$ g cada) e transferidos para duas bombas de teflon previamente descontaminadas. Foram adicionados $9 \mathrm{~mL}$ de ácido nítrico $65 \%, 2 \mathrm{~mL}$ de peróxido de hidrogênio $30 \%$ e $3 \mathrm{~mL}$ de ácido fluorídrico $40 \%$. A mistura foi então deixada em repouso durante 30 minutos com a tampa semiaberta. Após esse período, as entrada em operação do sistema de despoeiramento da Siderúrgica GERDAU (antiga Aços Finos Piratini), esse sistema entrou em operação no ano de 2000.

Charqueadas, enquanto que a outra estação, denominada (DP - DEPREC), instalada a cerca de $7 \mathrm{~km}$ à jusante do vento predominante (SE) em relação à usina termelétrica, em uma pequena vila no município de Triunfo com predominância de área verde. (Estações de monitoramento e localização da usina conforme Figura 1).

dados meteorológicos com as variáveis de Temperatura $\left({ }^{\circ} \mathrm{C}\right)$, Pressão Atmosférica $(\mathrm{mmHg})$, precipitação $(\mathrm{mm})$, Velocidade do Vento $\left(\mathrm{m} . \mathrm{s}^{-1}\right)$ e direção do vento são apresentados nas Tabelas S1 e S2 (Anexo, Material Suplementar). Os critérios para a seleção dos filtros PTS para a análise de metais foram baseados nas máximas concentrações de PTS, em diferentes períodos caracterizando as mudanças das tecnologias de controle utilizadas.

Para a amostragem de Partículas inaláveis (PM 10) da Estação Arranca é utilizado o equipamento BAM-1020 que mede e armazena automaticamente as concentrações de partículas em suspensão, utilizando o método de atenuação de raios beta. É um método designado pela EPA dos EUA como método equivalente Federal para monitoramento de PM10. O número designado para o BAM-1020 é EQPM-0798-122. (EPA, 2016).

bombas foram fechadas e colocadas para aquecer a uma temperatura de $150^{\circ} \mathrm{C}$ por um período de 6 horas em bloco digestor. Após esse período, as amostras foram resfriadas e então adicionados $4 \mathrm{~mL}$ de ácido bórico $20 \%$, para eliminar excesso de ácido fluorídrico que possa ter ficado na mistura. Depois dessa adição, as bombas retornaram para o bloco e foram aquecidas por mais 2 horas a $150^{\circ} \mathrm{C}$. A seguir, as amostras foram resfriadas, transferidas quantitativamente para falcons 
previamente descontaminados e volume completado para $50 \mathrm{~mL}$ com água deionizada (MiliQ, Milipore). Antes da leitura por ICP MS, as amostras foram centrifugadas e diluídas com ácido nítrico 5\%. Juntamente com as amostras, foi realizada a abertura de $1 / 8$ de filtros brancos para verificação da contaminação de metais provenientes do material de fabricação do filtro (fibra de vidro).

A identificação da composição do material particulado através da análise da morfologia foi realizada por MEV-EDS (Philips e modelo XL 30 Foram submetidos à análise morfológica 6 filtros da Estação Arranca Toco e 5 filtros da Estação DEPREC. A partir das imagens obtidas, foi realizada uma comparação das imagens das partículas encontradas nesses filtros com as imagens de trabalhos publicados relativos a caracterização morfológica de cinzas leves e particulados pesquisados em áreas com características industriais.

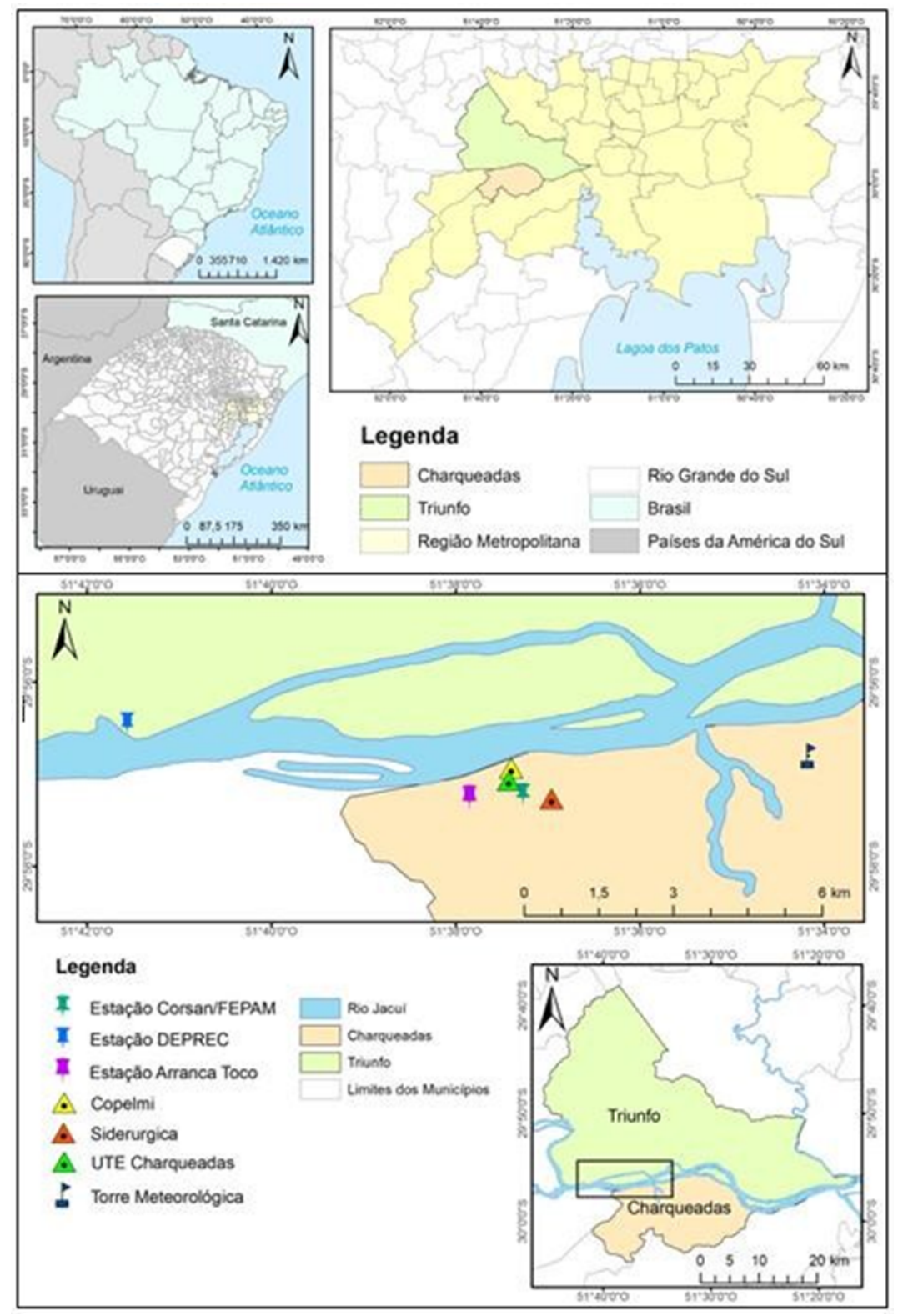

Figura 1

Mapa do Brasil, do Rio Grande do Sul, região Metropolitana de Porto Alegre, principais fontes emissoras no município de Charqueadas e Estações de Monitoramento da Qualidade do Ar. 


\section{RESULTADOS E DISCUSSÃO}

\subsection{PARTÍCULAS TOTAIS EM SUSPENSÃO (TSP)}

$\mathrm{Na}$ Figura 2 são mostrados os resultados da média geométrica anual de PTS, obtidos nas duas estações de amostragem no período de 1996 a 2015, AT $(\mathrm{n}=1.440)$ e DP $(n=792)$ bem como os padrões de qualidade do ar da legislação brasileira e a geração em MW da Usina Termelétrica. Observa-se nos resultados do monitoramento que houve ultrapassagens do padrão secundário (60 $\mu \mathrm{g} / \mathrm{m}^{3}$ ) de qualidade do ar na média geométrica anual nos anos de 1996 e 1997 na estação AT, enquanto que, na estação DP a média geométrica anual atendeu o padrão de qualidade nos 20 anos avaliados.

Entretanto, em alguns anos, como no ano de 2011, a média anual de TSP voltou a subir mesmo após a implantação das novas tecnologias. Um dos fatores que contribuíram para isso foram as cinzas provenientes da erupção do vulcão chileno Puyehue Córdoniva Caulle cujas cinzas finas atingiram Porto Alegre e região metropolitana nos meses de junho e outubro de 2011. (CARDOSO et al 2013; FEPAM, 2014). Neste mesmo ano, a termelétrica apresentou a menor geração de energia dentre todos os anos avaliados, consequentemente a emissão foi inferior. É possível que, além do vulcão, outros fatores e fontes, além da termelétrica, tenham contribuído para o resultado de material particulado encontrado. $\mathrm{O}$ maior valor de geração termelétrica no período analisado foi nos anos de 2000, 2014 e 2015, não sendo estes os anos em que a média da concentração das partículas totais em suspensão no ar apresentou as maiores concentrações. Cabe destacar que mesmo quando se avalia os resultados das médias mensais de concentração de PTS e de geração de energia (Fig. S1 a S4, Mat. Suplementar), não se observa correlações significativas entre esses parâmetros. Esses dados sugerem que os fatores climáticos e a presença de outras fontes emissores de PTS devem ter influência na qualidade do ar da região em relação a esse parâmetro.

O resultado das análises estatísticas da concentração de Material particulado total em suspensão nas Estações Arranca Toco (AT) e DEPREC (DP) para os 20 anos avaliados são apresentados nas Tabela S3 (Material Suplementar). A magnitude do desvio padrão obtido ano a ano indicam que os dados da estação Arranca Toco tem uma maior variabilidade das medições em relação à média anual e não varia de acordo com o tamanho da amostra. Por outro lado, o erro padrão da média da estimativa do desvio padrão, diminui com o aumento da amostra, refletindo o aumento da precisão da estimativa, quando há um maior número de amostragens. Os resultados da curtose encontrados para $\mathrm{o}$ conjunto de dados mostram na maioria dos anos avaliados uma curva de distribuição de frequência leptocúrtica, onde os dados estão fortemente em torno da moda.

Entretanto, os anos 1997, 1999, 2006 e 2008 para a Estação DEPREC e 2005 para as duas estações, apresentaram curva platicúrtica, quando os dados estão fracamente em torno da moda. Quanto a assimetria dos dados os resultados de ambas estações não apresentaram resultados com distribuição simétrica.

Para comparação dos resultados estatísticos entre as duas estações avaliadas, foi realizado teste de hipótese utilizando uma distribuição t de Student (não apresentado). Os testes foram realizados comparando as duas estações (AT e DP) ano a ano. A construção do teste de hipótese é feita a partir da seleção da hipótese alternativa (H1) e da hipótese de Nulidade $\left(\mathrm{H}_{0}\right)$. A hipótese alternativa $(\mathrm{H} 1)$ é a afirmação daquilo que queremos comprovar. Sendo assim, no caso H1, seria: existe diferença significativa entre a média da concentração de particulados nas duas estações de monitoramento de qualidade do ar. A hipótese de nulidade $\mathrm{H}_{0}$ é a negação daquilo que queremos comprovar. Sendo assim, nesse caso $\mathrm{H}_{0}$ seria: não existe diferença significativa entre a média da concentração de particulados das duas estações. O nível de significância do teste é definido como a probabilidade de erro do referido teste. Foi utilizado um nível de significância de 5\%. Então, para a comparação das duas médias, se o nível $\mathrm{p}$ calculado for menor do que 5\%, tem-se que o valor encontrado está dentro da zona de rejeição de $\mathrm{H}_{0}$ ou seja, aceita-se $\mathrm{H} 1$, indicando que existe diferença significativa entre as médias avaliadas. Os resultados desse teste indicaram que há diferença significativa das médias das duas estações para os resultados dos 20 anos avaliados. 


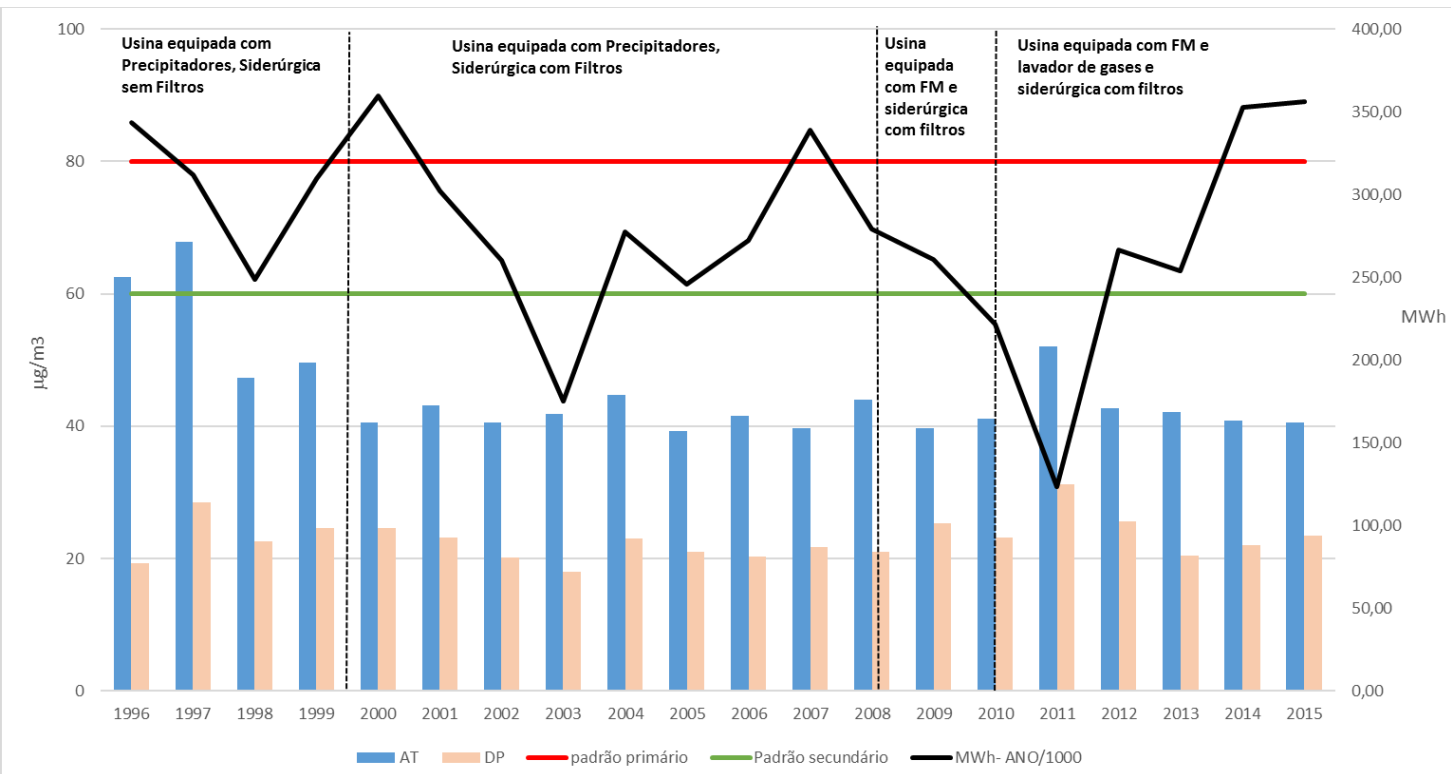

Figura 2

Concentrações médias geométricas anuais de TSP nas estações Arranca Toco e DEPREC e a geração anual de energia pela Termochar em MWh. Estão indicados os valores dos padrões primários e secundários de qualidade do ar para PTS (CONAMA 003/1990) e o controle nas principais fontes de emissão da região.

Com relação a interferência do regime de chuvas na qualidade do ar, estudos anteriores indicam que não há uma variação sazonal significativa na precipitação pluviométrica na cidade de Charqueadas. Ferraro e Hasenack (2000) realizaram uma análise climática na cidade de Charqueadas através de postos pluviométricos instalados com informações continuadas no período de 1985 a 1992. O resultado dessa avaliação mostrou que o período mais chuvoso é na primavera $(167 \mathrm{~mm})$ seguido pelo inverno $(123 \mathrm{~mm})$. As estações de verão e outono não apresentaram diferenças significativas no volume pluviométrico com valores de 115 e $112 \mathrm{~mm}$, respectivamente.

\subsection{PARTICULADO INALÁVEL (PM 10)}

A avaliação das partículas inaláveis foi realizada com dados obtidos na Estação Arranca Toco de 2010 a 2015. Para apresentação dos dados foi utilizado diagrama box plot (figura 3). A média aritmética dos dados obtidos nesta estação mostra que os dados de PM10 obtidos estão dentro dos padrões de qualidade requeridos (CONAMA 03/1990). O valor permitido é de $50 \mu \mathrm{g} / \mathrm{m}^{3}$ na média aritmética anual para padrão primário e secundário, enquanto que o máximo anual permitido para esse poluente é de $150 \mu \mathrm{g} / \mathrm{m}^{3}$ em um tempo de amostragem de $24 \mathrm{~h}$, valor ultrapassado no mês de outubro no ano de $2011\left(240 \mu \mathrm{g} / \mathrm{m}^{3}\right.$, outlier $)$, na ocasião da
Há registro de dados de pluviometria, na estação meteorológica instalada pela empresa na região (Figura1), somente a partir de 2004. Não houve nesse período uma regularidade na coleta de informações dos dados de chuva nessa estação meteorológica. Em muitos meses não há nenhuma informação desse parâmetro, prejudicando uma avaliação sobre a influência da chuva na redução do material particulado medido nas estações. Por outro lado, os dados corroboram os estudos realizados anteriormente, pois indicam que os maiores volumes de chuva ocorrem na estação da primavera, nos meses de outubro, novembro e dezembro (Figuras S1 a S4, Material Suplementar - Anexo).

chegada das cinzas do vulcão Chileno na RMPA.

Comparando 404 amostragens de PM10 e TSP realizadas no período de 2010 a 2015, na Estação Arranca Toco, observa-se que as partículas PM 10 representam em média $66 \%$ da concentração obtida nas amostragens de particulados totais. O gráfico da figura 4 tem o objetivo de mostrar essa proporção entre PM10 e PTS para o período avaliado.

Em relação a eventual influência da pluviometria nas concentrações de PM10, no material suplementar apresentamos na figura S5 o gráfico com os dados mensais de PM10 e volume de chuva de 2010 a 2015. Embora esse 
período tenha uma maior representatividade de dados de chuva do que nos anos anteriores, não há dados suficientes de chuva do período em estudo para uma avaliação mais segura da influência da chuva na qualidade do ar para o parâmetro PM10. Na média mensal, os maiores valores de PM10 são aqueles que ficaram acima de $45 \mu \mathrm{g} / \mathrm{m}^{3}$ e ocorreram nos meses de agosto de 2010 e agosto de 2012, mês da estação de inverno onde tipicamente ocorre a inversão térmica.

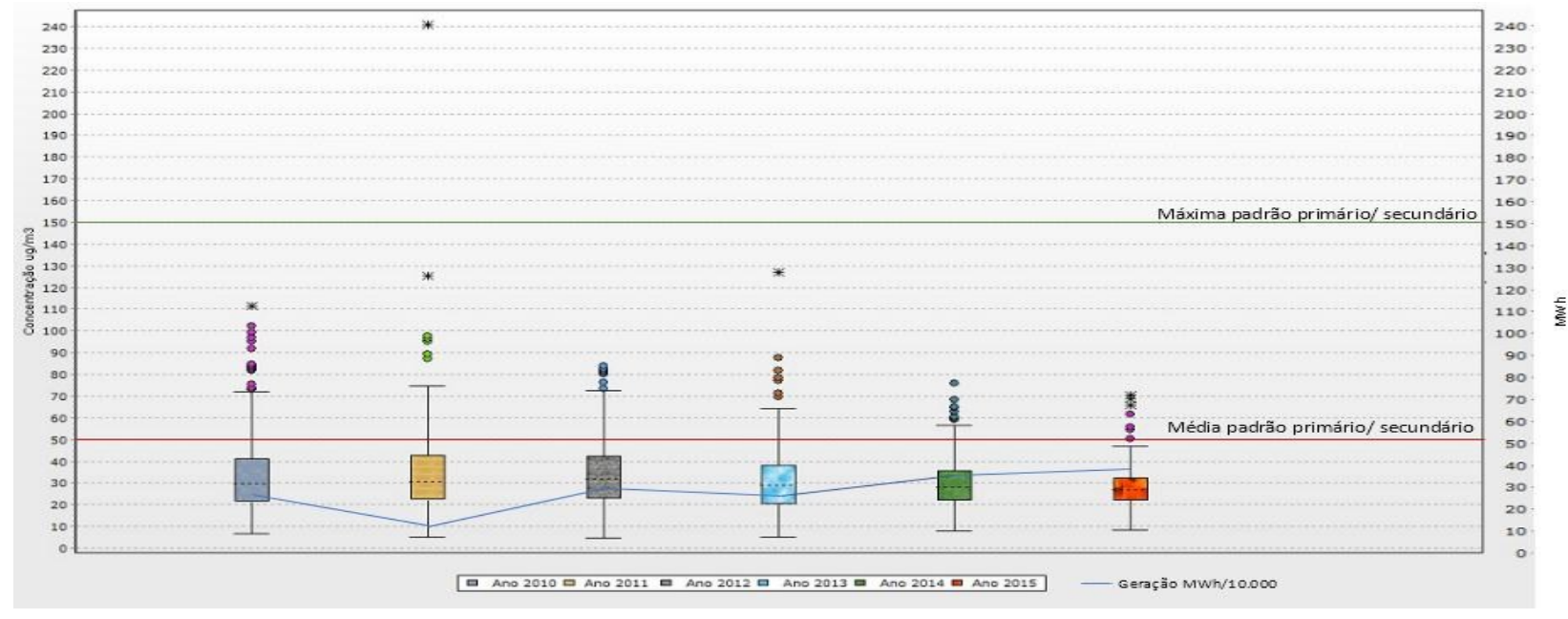

Figura 3

Concentrações média e máxima anual do PM10 (Estação AT), padrão máximo e média anual (CONAMA 03/90) e geração de energia da termelétrica pela UTCH no período.

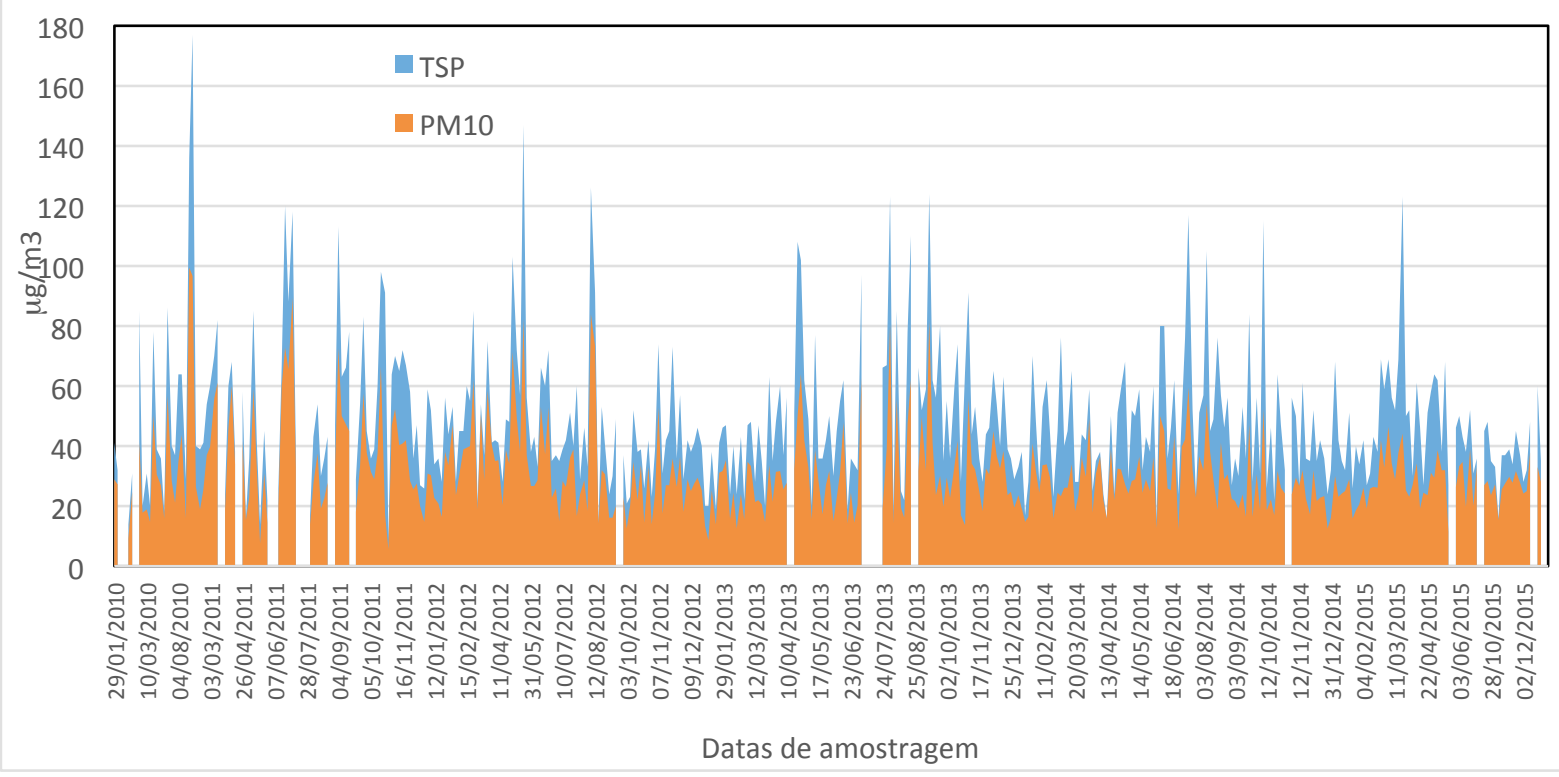

Concentrações de TSP e PM10 ( $n=440)$ dados diários (24 h) na Estação AT, no período de 2010

\subsection{CONCENTRAÇÃO DOS ELEMENTOS TRAÇO NO TSP}

Para a avaliação dos metais foram analisadas 40 amostras de TSP das estações, sendo 25 amostras da Estação Arranca Toco e 15 da Estação DEPREC contemplando respectivamente os períodos de 2008 a 2015 e 2009 a 2015. A estatística descritiva foi utilizada para uma avaliação inicial das informações numéricas obtidas das concentrações dos elementos químicos nos filtros analisados nas estações Arranca Toco (Tabela S4, Mat. Supl.) e DEPREC (Tabela S5).

A comparação dos dados das duas estações (figura 5) demonstra que na média das concentrações de todos os elementos analisados. Para que todos os elementos 
químicos pudessem ser mostrados no mesmo gráfico foi adotada a escala logarítmica. Os resultados obtidos na estação Arranca Toco são maiores do que na estação DEPREC. Os elementos de maior concentração em ambas as estações são o ferro seguido do manganês, que apesar da alta concentração é de menor preocupação em relação à saúde humana. Essas maiores concentrações podem estar relacionadas a sua não vaporização durante a combustão do carvão, permanecendo nas cinzas. Os óxidos de ferro, representam em torno de $3 \%$ da composição da cinza leve produzida na termelétrica (Rohde et.al). Os elementos $\mathrm{Be}$, $\mathrm{Co} \mathrm{e} \mathrm{Se}$, foram os que apresentaram os menores valores, todos com concentrações inferiores a $1 \mathrm{ng} / \mathrm{m}^{3}$.

As concentrações apesentaram grande variação nas amostras analisadas. $\mathrm{Na}$ amostragem do dia 08/08/2012 o teor de ferro apresentou a maior concentração $\left(7.728 \mathrm{ng} / \mathrm{m}^{3}\right)$ no material particulado da Estação Arranca Toco dentre todas as amostras analisadas. Nesse dia a termelétrica estava com uma das menores geração e consequentemente um baixo consumo de carvão, situação também verificada nos dias que antecederam essa amostragem.

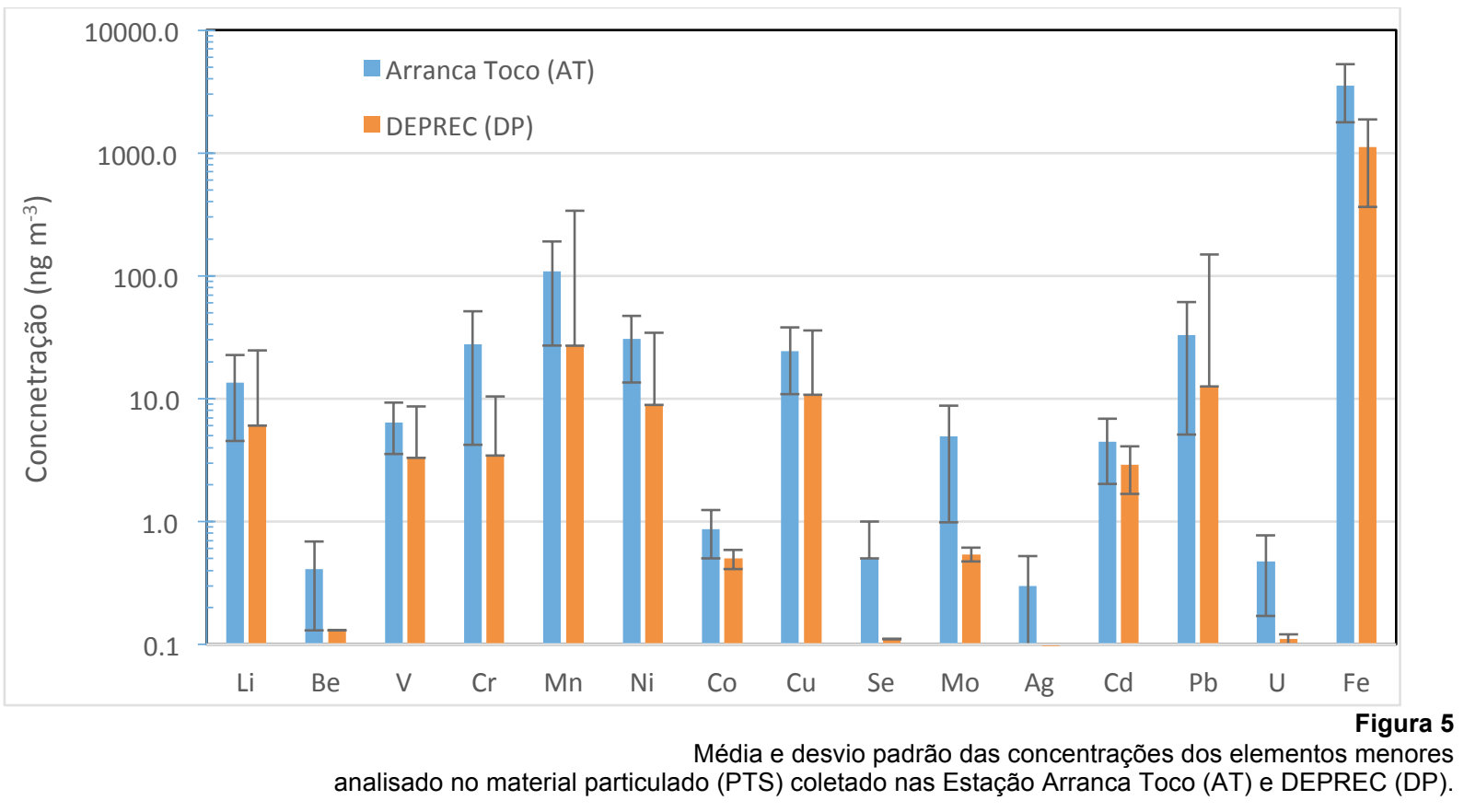

$\mathrm{Na}$ legislação Federal não há limites estabelecidos para elementos traço no material particulado atmosférico. A legislação do estado de São Paulo prevê padrão, na média aritmética anual, para o elemento chumbo, de $0,5 \mu \mathrm{g} / \mathrm{m}^{3}-\left(500 \mathrm{ng} / \mathrm{m}^{3}\right)$ enquanto que a USA EPA definiu como padrão para o chumbo o limite de $150 \mathrm{ng} / \mathrm{m}^{3}$ na média móvel trimestral. A comunidade Europeia estabelece valores anuais de referência de qualidade do ar para a concentração dos elementos Arsênio (6 $\left.\mathrm{ng} / \mathrm{m}^{3}\right)$, Cádmio $\left(5 \mathrm{ng} / \mathrm{m}^{3}\right)$, Níquel $\left(20 \mathrm{ng} / \mathrm{m}^{3}\right)$ e Chumbo $\left(0,5 \mu \mathrm{g} / \mathrm{m}^{3}\right)$. A média dos valores encontrados nesse estudo estão dentro do recomendado para o $\mathrm{Cd}$ e acima $\left(30 \mathrm{ng} / \mathrm{m}^{3}\right)$ do recomendado para Ni na estação AT.

As análises de elementos traço mostraram que a Estação Arranca Toco é mais impactada pela atividade industrial da região. $\mathrm{O}$ manganês e o ferro tiveram o resultado mais expressivo nas duas estações, são elementos que não vaporizam mesmo nas altas temperaturas de combustão. Outros elementos analisados como o $\mathrm{Cd} \mathrm{e} \mathrm{Pb}$, fazem parte de um grupo de elementos que são volatilizados durante a combustão e condensam sobre a superfície das cinzas sendo enriquecidos nestas partículas. Já o $\mathrm{Ni}$, o $\mathrm{Cr}$, o $\mathrm{Be}$ e o $\mathrm{Co}$, fazem parte de um grupo intermediário, entre os que não são vaporizados ou que são enriquecidos sobre as cinzas leves. (Pires, 1990; Godoy et al., 2005).

Além de ter origem na queima de fósseis, já há comprovação da emissão de metais por diversos processos industriais (Maycon et al., 2014) ou pelo uso de material industrializado, como o cromo que pode estar presente devido a origem em fundição de metais e produção de cimento, outros elementos como o $\mathrm{Cd}$ e $\mathrm{Ni}$ estão também associados a utilização de derivados de petróleo, assim como o $\mathrm{Cu}$ associado a queima de resíduos. (Osório et.al.2015) 
A presença de cádmio na atmosfera está relacionada a diferentes causas como a atividade vulcânica, incêndios florestais, emissões de indústrias de ferro e aço, combustíveis fósseis (carvão, óleo, gás, turfa), madeira, cimento e fertilizantes fosfatados entre outras. $O$ cádmio e seus compostos ocorrem na atmosfera na forma de material particulado suspenso, embora apresentem baixa pressão de vapor, o $\mathrm{Cd}$ é um elemento volátil e pode ser emitido como vapor em processos que envolvem temperaturas extremamente altas, como indústria de ferro e aço. (CETESB, 2012) O níquel está disponível na natureza no solo, em fumaças vulcânicas e no fundo dos oceanos. Também pode ser lançado no meio ambiente em resíduos de indústrias que o utilizam como matéria prima. Dentre as indústrias que geram resíduos com níquel, destacamos as do setor de papel, refinarias de petróleo, siderúrgicas e processos de galvanoplastia (Figueiredo, 2013).
Comparando-se as concentrações de $\mathrm{Cu}, \mathrm{Ni}, \mathrm{Mn}, \mathrm{Pb}$ e $\mathrm{Cd}$ obtidas em estudo realizado pela Fundação Estadual de Proteção Ambiental (VASSILIOU et.al. 2000), na estação denominada Centro ao lado da atual Arranca Toco no período de 1994 e 1995, as concentrações atuais foram entre 1,3 e 59 vezes inferiores. Esses resultados podem indicar uma diminuição das emissões industriais entre os períodos estudados.

Em outro estudo realizado pela FEPAM com dados de 2010 e 2011 na estação CORSAN (figura 1) na cidade de Charqueadas (CARDOSO et al., 2014), foram analisados os elementos $\mathrm{Cd}, \mathrm{Cr}, \mathrm{Ni}, \mathrm{Pb}, \mathrm{Zn}, \mathrm{Mn}, \mathrm{Cu}$ e Fe nas partículas PM10. Os resultados indicaram que a qualidade do ar monitorada nessa estação é compatível com áreas urbanas industriais, e que o aumento de material particulado não implica no aumento dos elementos menores analisados. Da mesma forma que neste estudo os elementos mais abundantes encontrados foram o Ferro e o Manganês.

\subsection{CARACTERIZAÇÃO MORFOLÓGICA E COMPOSIÇÃO ELEMENTAR DO TSP}

A partir das imagens obtidas por MEV das amostras de PTS observou-se a presença de partículas heterogêneas com diferentes formas e tamanhos, provavelmente pela ampla faixa de granulometria compreendida nesse tipo de amostra $(\sim 0,1$ a $100 \mu \mathrm{m})$. As análises das partículas individuais mostram que os elementos predominantes foram o silício e o alumínio, esses elementos são os componentes predominantes no cinza volante e no caso do silício está presente na composição dos filtros de fibra de vidro utilizados na amostragem. O ferro também é um elemento recorrente nas amostras avaliadas. Outro metal presente em algumas amostras foi o zinco, metal associado a processos de galvanização do aço ou do ferro e também a processos siderúrgicos (Gajghate \& Bhanarkar, 2005). Esse metal já foi identificado em estudos realizados em 2009 no material suspenso e na precipitação úmida da RMPA (Osorio et al., 2015). Cabe destacar que a presença de $\mathrm{Zn}$ ocorre mesmo nas amostragens nos períodos em que não há geração termelétrica, o que pode ser um indicador que há outra fonte responsável pela emissão deste poluente.

A imagem (não apresentada) da composição química da amostra do dia 31/07/2013, da Estação Arranca Toco, mostra a presença de $\mathrm{Si}, \mathrm{Al}, \mathrm{K}, \mathrm{Mg}, \mathrm{Ca}$ e $\mathrm{Sr}$, elementos de características com origem de ressuspensão de poeira do solo. No período em que ocorreu esta amostragem a usina termelétrica não estava gerando energia e a predominância do vento era sudeste, direção predominante do vento na região que favorece a captação de particulados proveniente das emissões atmosféricas da usina.

$\mathrm{Na}$ imagem (não apresentada) das partículas identificadas na amostragem de 26/03/2009 - Estação AT- foram identificados os elementos $\mathrm{Si}, \mathrm{Al}, \mathrm{K}, \mathrm{Mg}, \mathrm{Ca}, \mathrm{Sr}, \mathrm{Fe}, \mathrm{Zn}$ e Ti. Nesse dia a usina termelétrica estava com uma geração horária de 46,01 MW e o equipamento para controle do material nessa data eram os precipitadores eletrostáticos e a predominância dos ventos era sudeste, na direção onde estão localizadas as estações de monitoramento. A diferença identificada entre esta amostra e a do dia 31/07/2013 é a presença do titânio.

A Imagem das partículas identificadas na amostragem de 11/09/2013 da estação AT figura 6 foram identificados os elementos $\mathrm{Si}$, $\mathrm{Al}, \mathrm{Na}, \mathrm{K}, \mathrm{Mg}, \mathrm{Ca}, \mathrm{Sr}, \mathrm{Fe}, \mathrm{Zn}$ e Ti. A partir de outubro de 2010 a usina termelétrica estava equipada com Filtros de manga e Lavador de Gases. Na data dessa amostragem a geração foi de 41,71_MWh. A predominância dos ventos durante essa amostragem era sul-sudeste. 

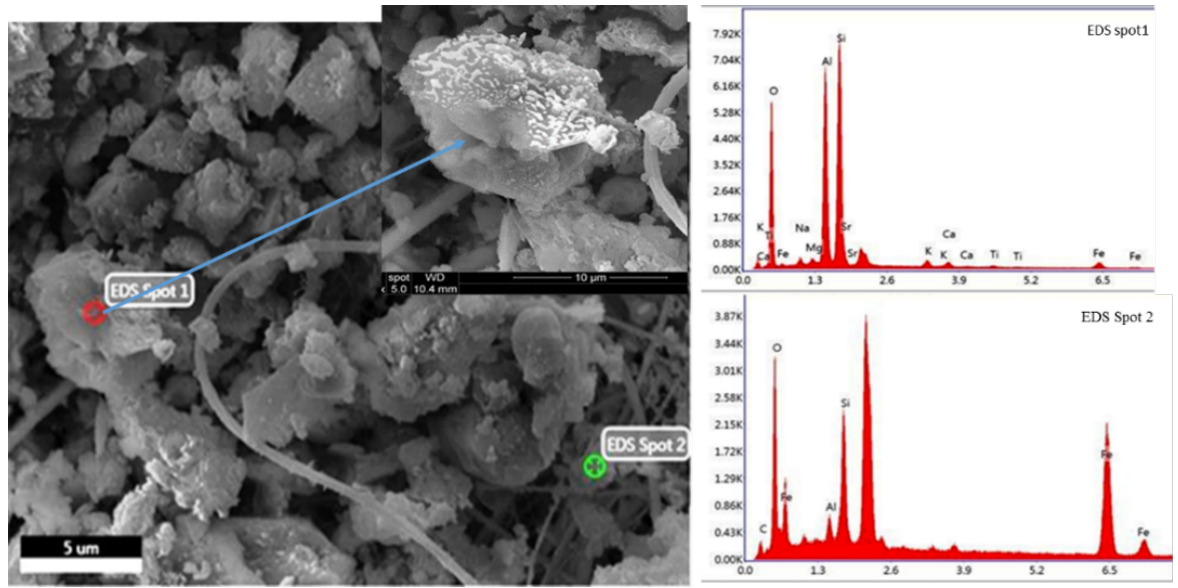

Figura 6

Imagem das partículas identificadas na amostragem de 11/09/2013 (124 $\mathrm{mg} \mathrm{m}^{-3}$ ) Estação AT e espectros EDS indicados nos spots 1 e 2 .
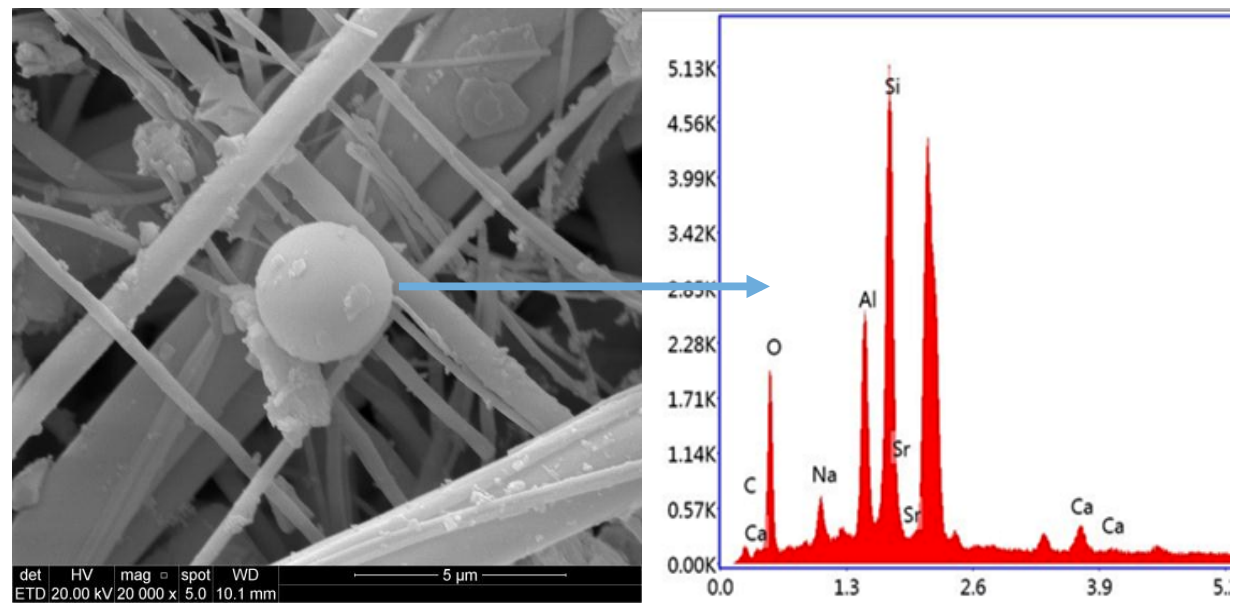

Figura 7

Imagem das partículas identificadas na amostragem de 19/10/2011 (98 $\left.\mathrm{mg} \mathrm{m}^{-3}\right)$ - Estação AT e espectro EDS
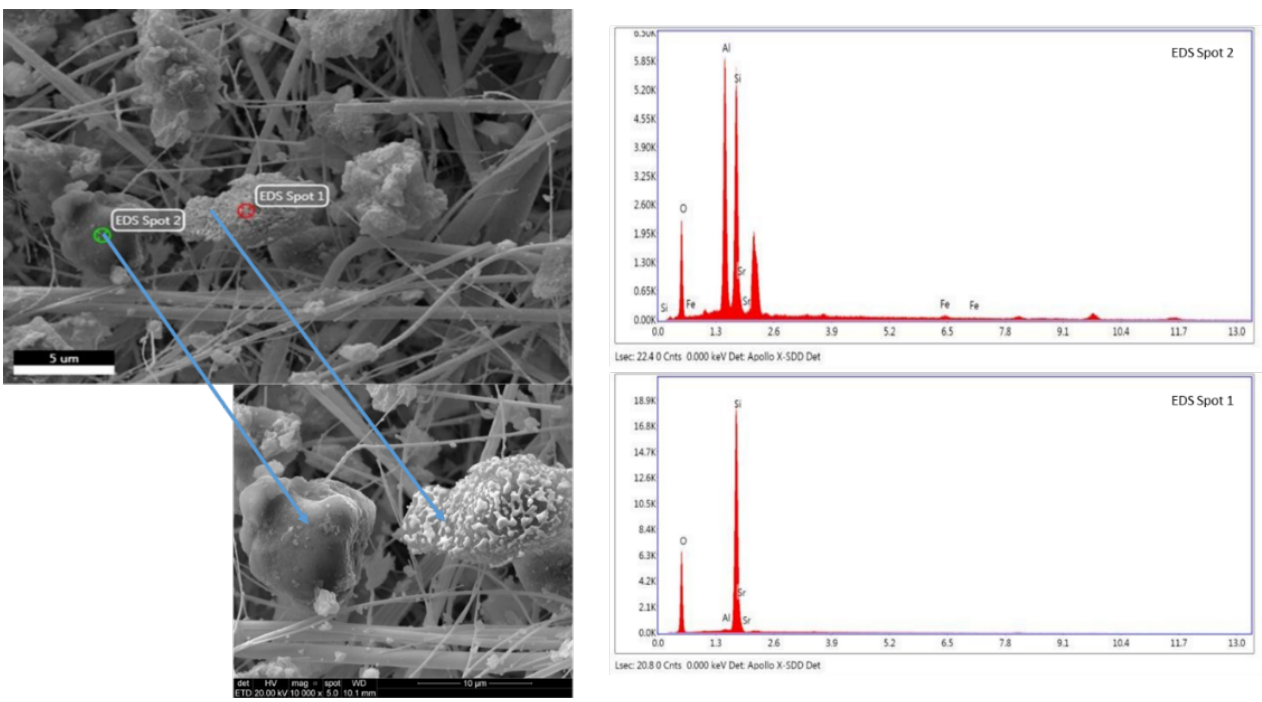

Figura 8

Imagem das partículas identificadas na amostragem de 07/12/2014 (101 $\left.\mathrm{mg} \mathrm{m}^{-3}\right)$ Estação DP e espectros EDS indicados nos spots 1 e 2 
Os elementos identificados na imagem das partículas da amostragem de 19/10/2011 da estação Arranca Toco, são os mesmos descritos nas amostragens anteriores. Durante essa amostragem a geração horária foi de 25,29 MWh e a usina estava operando equipada com filtros de manga e Lavador de Gases, a direção predominante do vento era Sul - sudeste. Nessa imagem (figura 7) foi possível visualizar uma cenoesfera, comumente encontrada em amostras de cinzas e carvão. (Paproki, 2009)

As partículas contendo $\mathrm{Si}, \mathrm{Al}, \mathrm{K}, \mathrm{Mg}$, $\mathrm{Ca}, \mathrm{Sr}, \mathrm{Fe}, \mathrm{Zn}, \mathrm{Ge}$ e Ti foram identificadas nas imagens (não apresentadas) da amostragem de 01/11/2009 - estação DP, nessa amostragem a Usina termelétrica estava operando e a geração horária era de 26,72 $\mathrm{MWh}$, nessa data o

\section{CONCLUSÃO}

O estudo apresentado indica que a adoção de tecnologias modernas de tratamento dos efluentes atmosféricos da termelétrica resultou em melhoria na qualidade do ar da região analisada.

Os resultados das duas estações na média geométrica anual estão abaixo do limite que estabelece a Resolução CONAMA para o padrão secundário, no entanto a estação DEPREC, mais afastada da usina, apresenta resultados ainda menores do que a estação Arranca Toco, localizada no centro urbano de Charqueadas e próxima à termelétrica. Também é possível observar que não há uma relação direta entre o aumento da geração de energia e o aumento da concentração de particulado total suspenso no ar.

Com relação ao PM10 amostrado na Estação Arranca Toco, não há amostragem desse poluente realizada antes das melhorias implantadas na usina, que possibilite uma comparação dos níveis de poluição antes e depois da instalação dos novos controles. No entanto esse é um poluente cuja a concentração nos grandes centros urbanos tem aumentado, fato não observado nos 6 anos amostrados na Estação Arranca Toco, pois há uma leve redução dos valores medidos o que pode ser um indicativo de que a eficiência do controle da emissão de finos pelos filtros de mangas

\section{AGRADECIMENTOS}

Agradecemos a Tractebel Energia pela disponibilização dos dados de qualidade do ar obtidos nas estações mantidas e operadas pela lavador de gases ainda não estava em operação, o controle ambiental eram os filtros de manga.

A direção predominante do vento era sul- sudeste. A Imagem das partículas identificadas nas imagens (não apresentadas) da amostragem de 16/11/2014 na Estação DEPREC compreendem os elementos $\mathrm{Si}, \mathrm{Al}$, $\mathrm{K}, \mathrm{Mg}, \mathrm{Ca}, \mathrm{Fe}$ e $\mathrm{Zn}$. A termelétrica não estava gerando energia nessa data e a direção predominante era sul-sudeste. Os elementos $\mathrm{Si}$, $\mathrm{Al}, \mathrm{Sr}$ e $\mathrm{Fe}$, foram os identificados na imagem da amostragem de 07/12/2014 (figura 8), nessa data, a usina tinha geração horária de 44,27 MWh, estava equipada com filtros de manga e FGD. A direção predominante do vento era Sul.

associado ao lavador de gases trouxe benefícios significativos na redução da parcela de poluentes que causam prejuízos à saúde humana.

As análises morfológicas do particulado total mostraram uma grande variedade de partículas devido à larga faixa de granulometria do material coletado e a ausência de diferença significativa entre as amostras das duas estações. Há semelhança entre as partículas analisadas e as encontradas em amostras de cinzas volantes e a material de ressuspensão do solo. $\mathrm{Na}$ composição elementar das partículas avaliadas foram encontrados os elementos metálicos $\mathrm{Fe}$ e $\mathrm{Zn}$ que, além da relação com as emissões da termelétrica podem estar relacionados as emissões de siderúrgica existente na região, uma vez que em amostragens em que a termelétrica estava fora de operação eles continuaram presentes nas amostras.

Para que os resultados sejam representativos, as variações climáticas têm que estar inseridas na avaliação bem como o conhecimento qualitativo e quantitativo das emissões da região estudada. Somente com a integração desses elementos o monitoramento ambiental poderá se tornar um instrumento auxiliar na gestão da qualidade do ar pelos órgãos responsáveis.

empresa. M.P. agradece ao CNPq pela concessão de bolsa de produtividade. 


\section{ANEXO - MATERIAL SUPLEMENTAR}

Tabela S1 - Geração da usina, condições meteorológicas e concentração de material particulado na Estação Arranca Toco das amostras selecionadas para caracterização química e morfológica. Local de Coleta: Estação Arranca Toco

\begin{tabular}{|c|c|c|c|c|c|c|c|}
\hline Data & $\begin{array}{c}\text { Concentração } \\
\mu \mathrm{g} / \mathrm{m}^{3}\end{array}$ & $\begin{array}{c}\text { Temperatura } \\
\text { Ar } \\
{ }^{\circ} \mathbf{C}\end{array}$ & $\begin{array}{c}\text { Pressão } \\
\text { mmHg }\end{array}$ & $\begin{array}{c}\text { Velocidade } \\
\text { Vento } \\
\text { m.s }\end{array}$ & $\begin{array}{c}\text { Direção } \\
\text { vento pred. }\end{array}$ & $\begin{array}{c}\text { Precipitação } \\
\text { Pluviométrica } \\
\text { (mm) }\end{array}$ & $\begin{array}{c}\text { Geração } \\
\text { MW }\end{array}$ \\
\hline 08/02/2009 & 111 & 24,0 & 759 & 2,09 & SSE - Sul Sudeste & 0,00 & 905,322 \\
\hline $26 / 03 / 2009$ & 140 & 23,1 & 758 & 2,01 & SE - Sudeste & 0,00 & $1.104,464$ \\
\hline $15 / 04 / 2009$ & 177 & 18,1 & 766 & 2,00 & S - Sul & 1,05 & 978,614 \\
\hline 03/03/2010 & 85 & 24,1 & 761 & 2,04 & SE - Sudeste & & 295,680 \\
\hline $18 / 08 / 2010$ & 136 & 18,6 & 761,7 & & & & $1.054,604$ \\
\hline $22 / 08 / 2010$ & 177 & 21,0 & 758 & & & & 886,951 \\
\hline $14 / 06 / 2011$ & 120 & 11,1 & 766,1 & & & & 599,826 \\
\hline 10/07/2011 & 118 & 12,0 & 761,1 & 1,00 & WSW-Oeste Sudoeste & 0,50 & 252,136 \\
\hline 04/09/2011 & 113 & 19,1 & 757,1 & 0,06 & SE - Sudeste & 22,05 & 4,574 \\
\hline 19/10/2011 & 98 & 19,1 & 765 & 2,00 & SSE - Sul Sudeste & 3,05 & 606,959 \\
\hline 09/05/2012 & 103 & 20,0 & 761 & 1,01 & E - Este & 0,00 & 598,282 \\
\hline 08/08/2012 & 126 & 18,0 & 762,1 & 1,06 & ESE - Este Sudeste & & 30,755 \\
\hline $23 / 04 / 2013$ & 108 & & & & & & 706,373 \\
\hline $31 / 07 / 2013$ & 123 & 14,0 & 459,1 & 0,09 & SE - Sudeste & 4,02 & 0,00 \\
\hline $21 / 08 / 2013$ & 110 & 18,1 & 758 & 1,09 & SSE - Sul Sudeste & & 658,529 \\
\hline $11 / 09 / 2013$ & 124 & 24,1 & 759,1 & 1,03 & SSE - Sul Sudeste & & $1.001,170$ \\
\hline $16 / 07 / 2014$ & 117 & 19,0 & 762 & 1,02 & SE - Sudeste & 0,04 & $1.044,719$ \\
\hline 06/08/2014 & 105 & 15,1 & 761 & 1,03 & SE - Sudeste & 0,02 & 658,040 \\
\hline 08/10/2014 & 115 & 23,0 & 758,1 & 2,00 & SE - Sudeste & 0,02 & $1.335,388$ \\
\hline $25 / 03 / 2015$ & 123 & 25,1 & 760 & 1,05 & SE - Sudeste & 0,02 & 669,102 \\
\hline 29/07/2015 & 98 & 17,1 & 764 & 0,07 & SSW - Sul Sudoeste & 0,02 & $1.214,851$ \\
\hline 02/08/2015 & 92 & 21,0 & 759 & 1,00 & SSE - Sul Sudeste & 0,00 & $1.361,040$ \\
\hline
\end{tabular}

Tabela S2 - Geração da usina, condições meteorológicas e concentração de material particulado na Estação DEPREC das amostras selecionadas para caracterização química e morfológica.

\begin{tabular}{|c|c|c|c|c|c|c|c|}
\hline Data & $\begin{array}{c}\text { Concentração } \\
\mu \mathrm{g} / \mathbf{m}^{3}\end{array}$ & $\begin{array}{c}\text { Temperatura } \\
\text { Ar } \\
{ }^{\circ} \mathbf{C}\end{array}$ & $\begin{array}{l}\text { Pressão } \\
\text { mmHg }\end{array}$ & $\begin{array}{l}\text { Velocidade } \\
\text { Vento } \\
\text { m.s }\end{array}$ & $\begin{array}{c}\text { Direção } \\
\text { vento pred. }\end{array}$ & $\begin{array}{l}\text { Precipitação } \\
\text { Pluviométrica } \\
\text { (mm) }\end{array}$ & $\begin{array}{c}\text { Geração } \\
\text { MW }\end{array}$ \\
\hline $16 / 08 / 2009$ & 54 & 22,4 & 755,4 & 1,08 & SSE - Sul Sudeste & 0 & 651,182 \\
\hline $25 / 10 / 2009$ & 63 & 18,1 & 759 & 4,02 & NNE - Nor Nordeste & 0 & 309,380 \\
\hline $01 / 11 / 2009$ & 97 & 25,0 & 756,1 & 2,04 & SSE - Sul Sudeste & 0 & 641,338 \\
\hline $18 / 04 / 2010$ & 60 & 23,1 & 761 & 1,03 & NE - Nordeste & 0 & 546,939 \\
\hline $22 / 08 / 2010$ & 91 & 21,0 & 758 & & & & 886,951 \\
\hline $23 / 10 / 2011$ & 89 & 24,1 & 762,1 & 0,07 & SE - Sudeste & 2 & 286,369 \\
\hline $06 / 11 / 2011$ & 58 & 23,0 & 761,1 & 2,06 & S - Sul & 1,05 & 403,535 \\
\hline $20 / 11 / 2011$ & 63 & 23,0 & 759 & 1,05 & SE - Sudeste & 1,05 & 280,560 \\
\hline $28 / 04 / 2013$ & 45 & 22,1 & 759 & 1,01 & ESE - Es Sudeste & & 990,786 \\
\hline $07 / 06 / 2013$ & 43 & 11,1 & 762,1 & 0,09 & S - Sul & & $1.059,834$ \\
\hline $20 / 10 / 2013$ & 64 & 24,0 & 753,1 & 1,08 & SE & & 687,321 \\
\hline $07 / 07 / 2013$ & 43 & 14,0 & 761,1 & 2,02 & SSE - Sul Sudeste & 72,02 & 313,736 \\
\hline $08 / 12 / 2013$ & 43 & 25,0 & 757 & 1,07 & SSW - Sul Sudoeste & 0 & $1.008,173$ \\
\hline $16 / 11 / 2014$ & 77 & 22,1 & 761,1 & 1,05 & SSE - Sul Sudeste & 0 & 0,000 \\
\hline $30 / 11 / 2014$ & 97 & 28,0 & 756,8 & 2,00 & ESE - Es Sudeste & 0 & 988,657 \\
\hline $07 / 12 / 2014$ & 101 & 27,1 & 757,1 & 1,04 & S - Sul & 0 & $1.062,470$ \\
\hline $25 / 01 / 2015$ & 79 & 26,1 & 756,1 & 2,01 & WSW - Oeste Sudoeste & 0 & $1.013,835$ \\
\hline $30 / 08 / 2015$ & 58 & 20,1 & 762 & 0,06 & SW - Sudoeste & 0 & $1.320,085$ \\
\hline
\end{tabular}



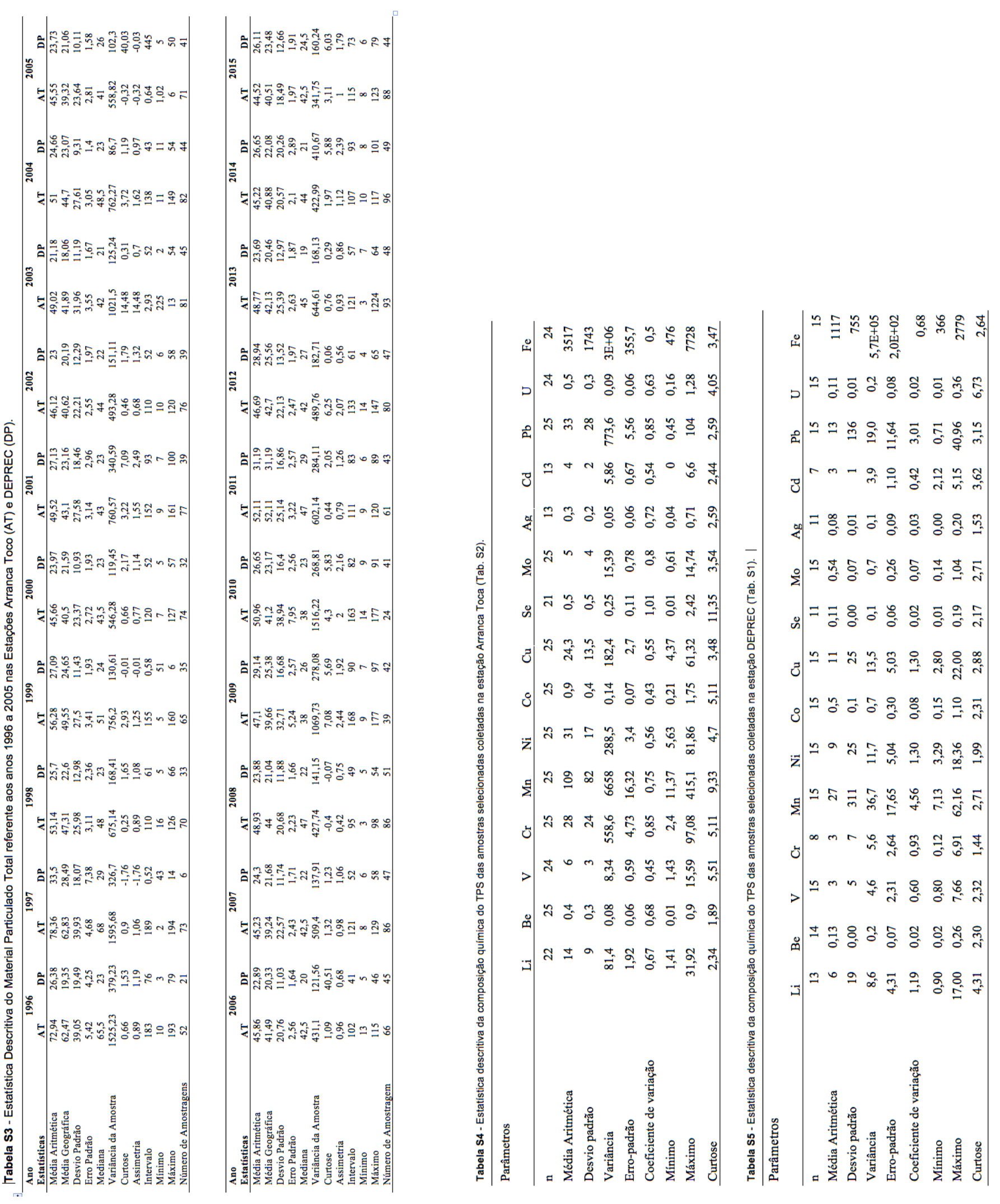


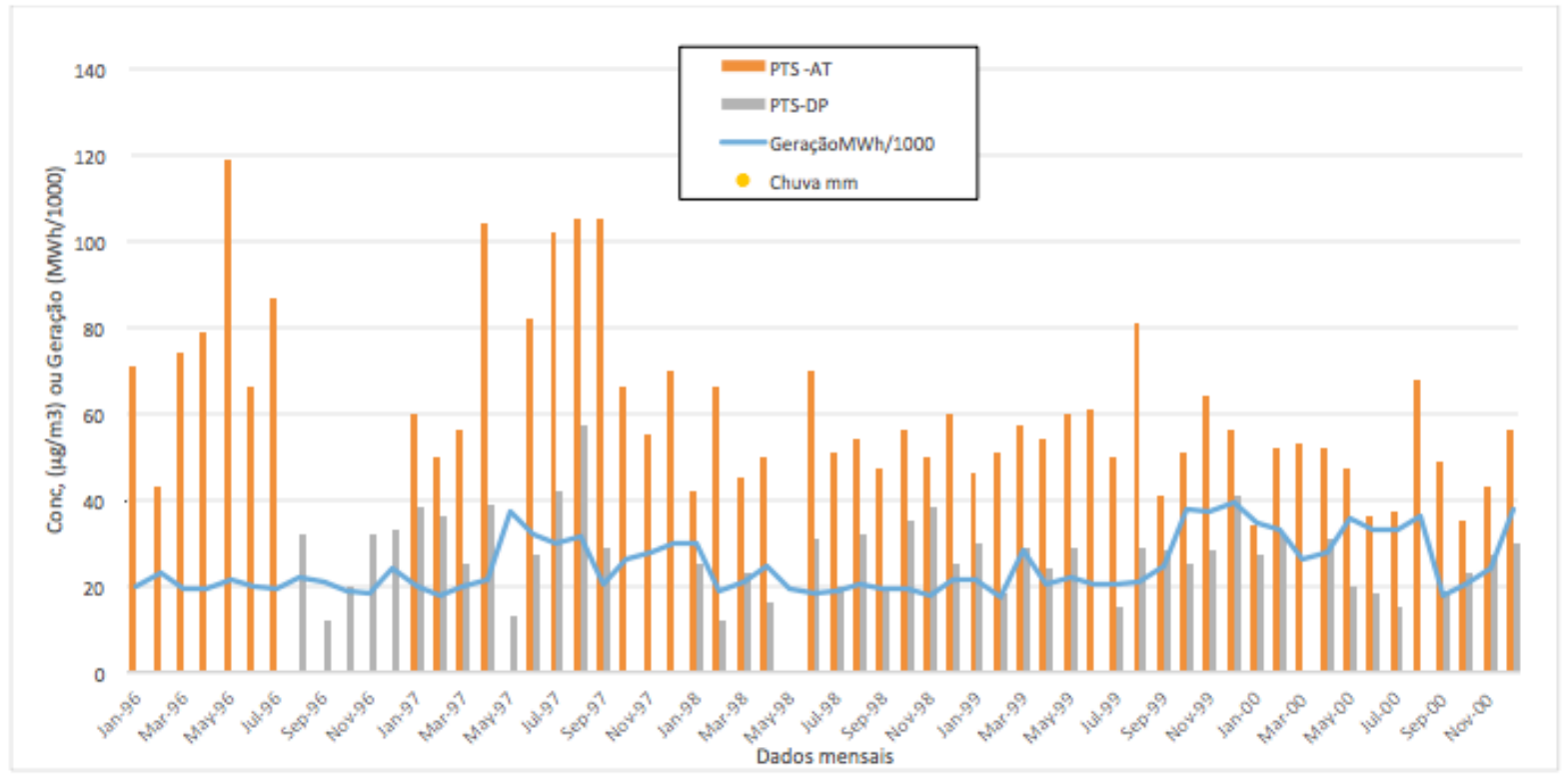

Figura S1

Concentrações médias geométricas mensais de TSP nas estações Arranca Toco (AT) e DEPREC (DP), geração mensal de energia pela Termochar e pluviometria (acumulado mês), referente ao período de janeiro 1996 a dezembro 2000.

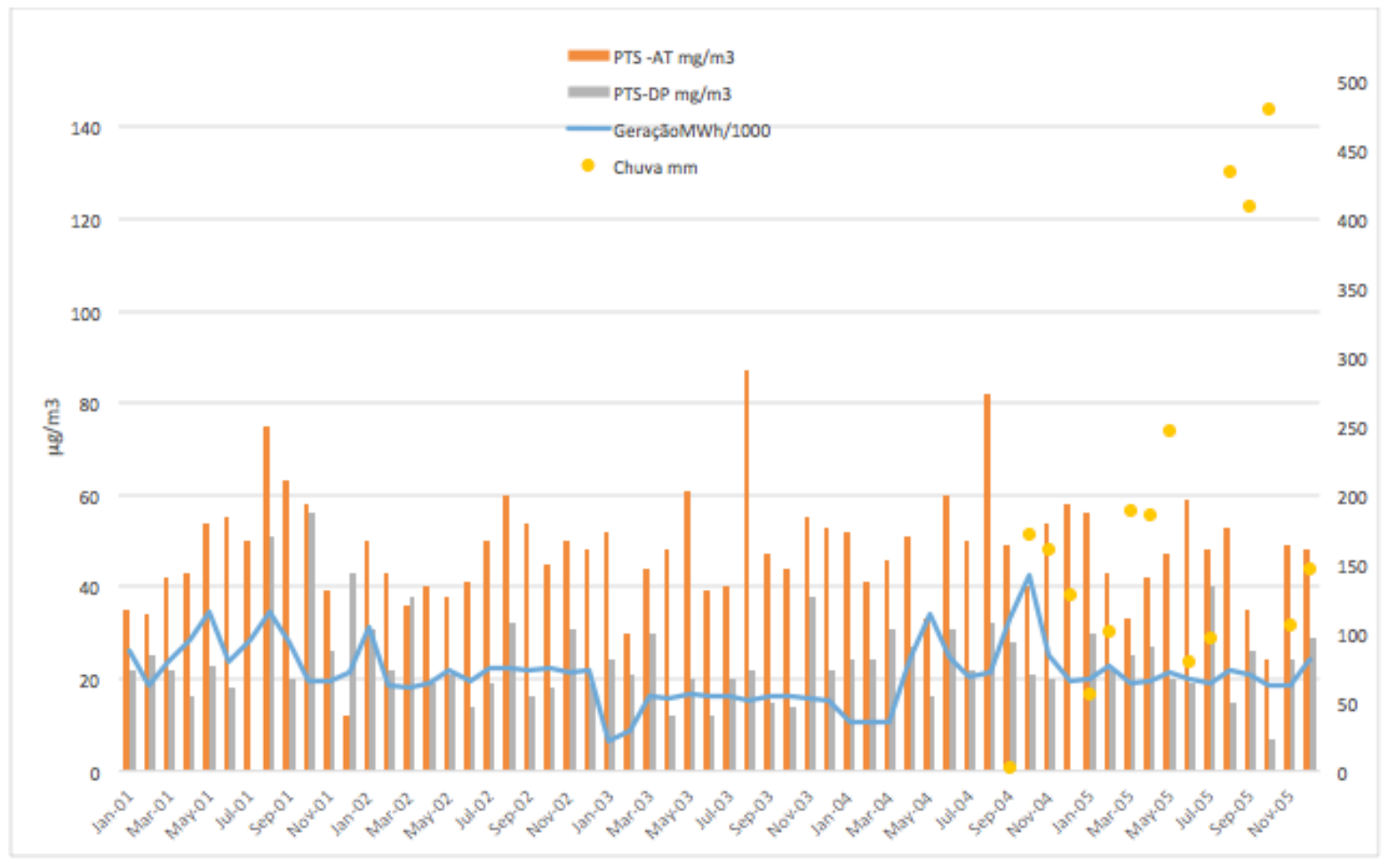

Figura S2

Concentrações médias geométricas mensais de TSP nas estações Arranca Toco (AT) e DEPREC (DP), geração mensal de energia pela Termochar e pluviometria (acumulado mês), referente ao período de janeiro 2001 a dezembro 2005 


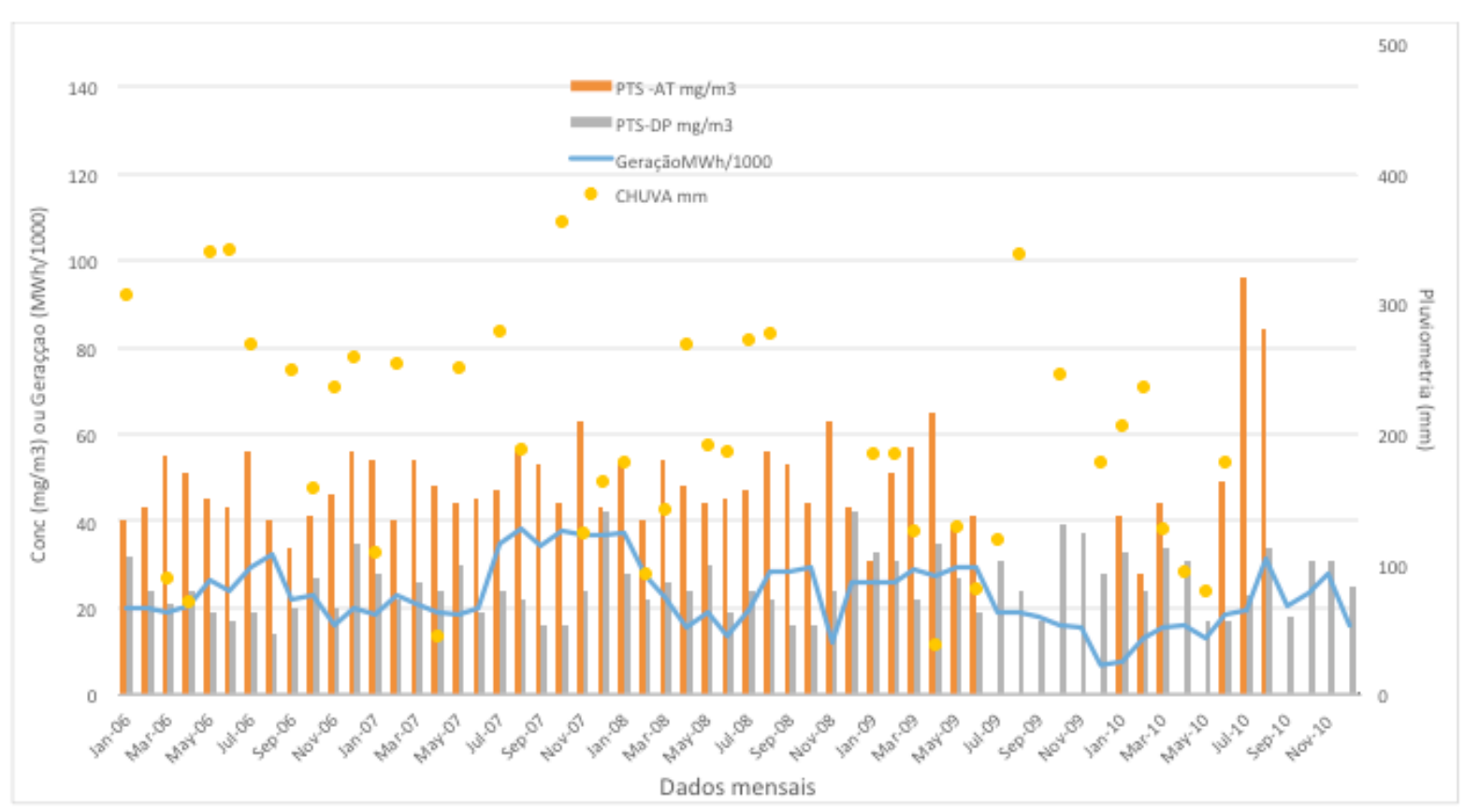

Figura S3

Concentrações médias geométricas mensais de TSP nas estações Arranca Toco (AT) e DEPREC (DP), geração mensal de energia pela Termochar e pluviometria (acumulado mês), referente ao período de janeiro 2006 a dezembro 2010.

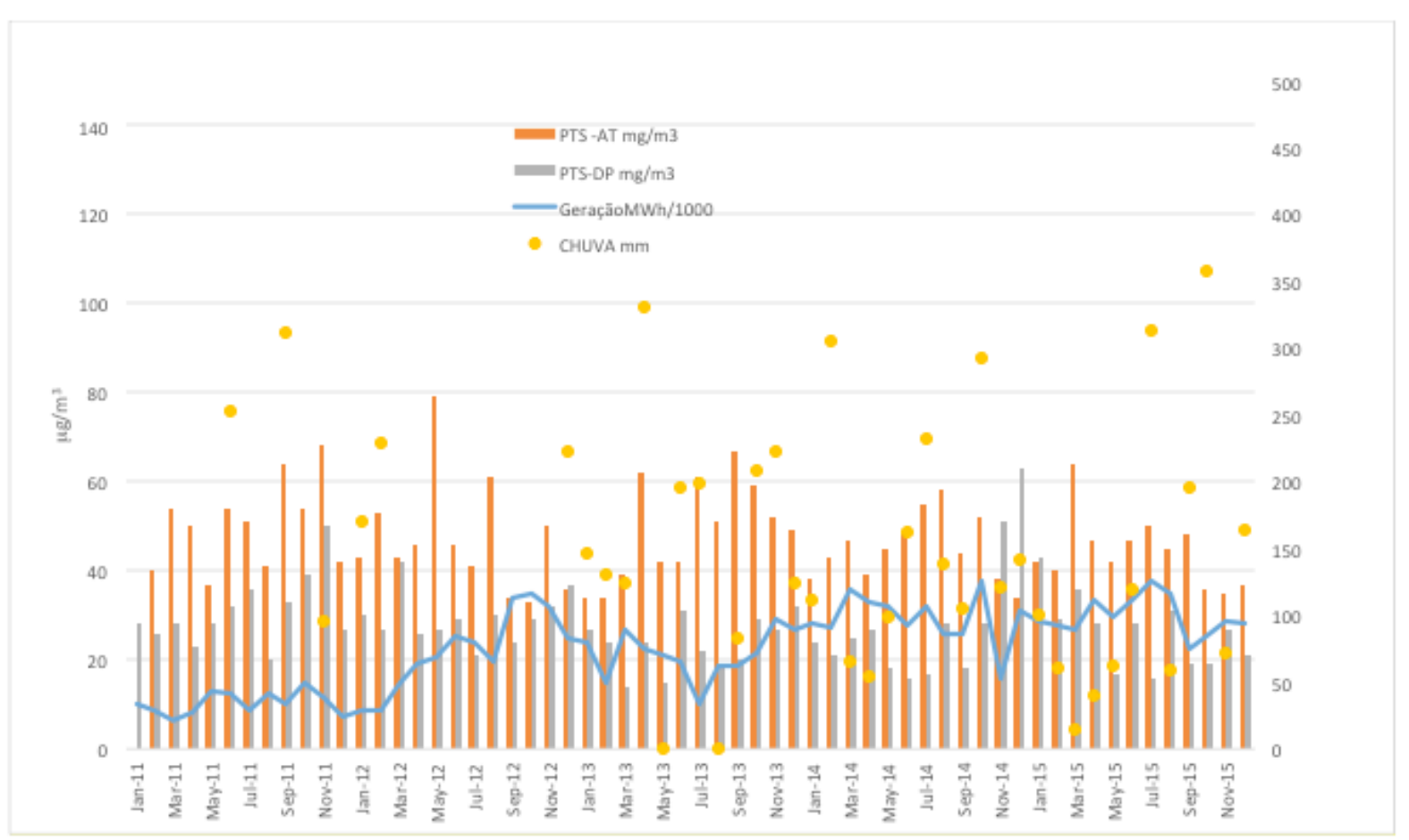

Figura S4

Concentrações médias geométricas mensais de TSP nas estações Arranca Toco (AT) e DEPREC (DP), geração mensal de energia pela Termochar e pluviometria (acumulado mês), referente ao período de janeiro 2011 a dezembro 


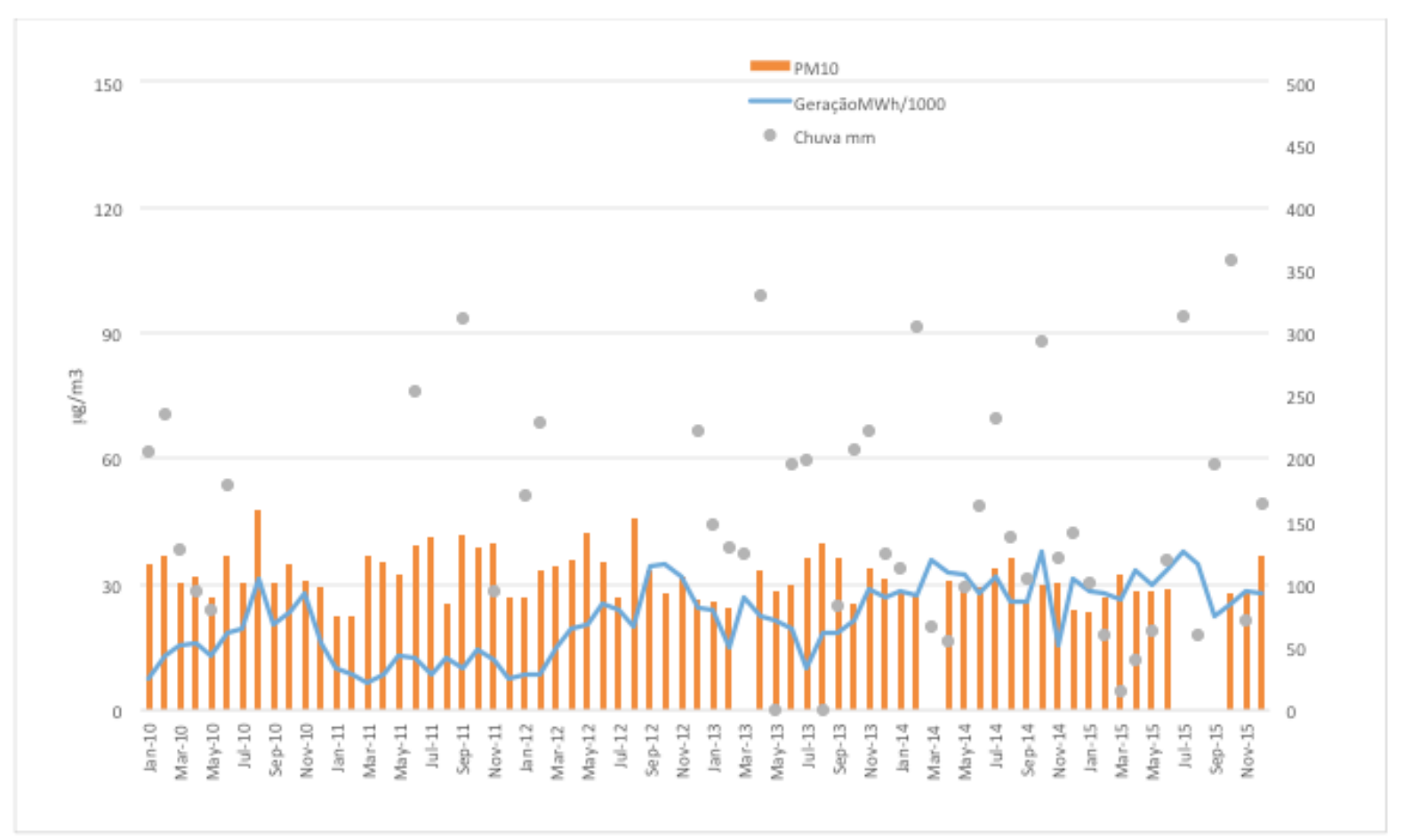

Figura S5 Concentrações médias geométricas mensais de PM10 nas estações Arranca Toco (AT) e DEPREC (DP), geração mensal de energia pela Termochar e pluviometria (acumulado mês), referente ao período de janeiro 2010 a dezembro 2015.

\section{REFERÊNCIAS}

ASSOCIAÇÃO BRASILEIRA DE NORMAS TÉCNICAS. NBR 9547: Material particulado em suspensão no ar ambiente- Determinação da concentração total pelo método amostrador de grande volume. Rio de Janeiro, 1998.

Baird, C. \& Cann M. 2011. Química Ambiental. $4^{\mathrm{a}}$ ed., Editora Bookman, Porto Alegre, 844 pp.

Cardoso, N.C.; Silva, I.M.C.O.; Carvalho, C.T.; Soares, N.B.; Rodrigues, M.L.K.; 2014. Avaliação do Teor de Material Particulado Atmosférico inalável $\left(\mathrm{MP}_{10}\right)$ na Região Metropolitana de Porto Alegre no Período 2010 - 2012. In: IX Simpósio Internacional de Qualidade Ambiental, 150p.

Cardoso, N.C.; Silva, I.M.C.O.; Carvalho, C.T.; Soares, N.B.; Rodrigues, M.L.K.; 2013. Comparação da qualidade do ar em dois municípios da Região Metropolitana de Porto Alegre afetados por diferentes contribuições antropogênicas, Porto Alegre, FEPAM em Revista. 7(1-2): 36-45.

CETESB, 2012. Cádmio e seus compostos. Disponível

em: http://cetesb.sp.gov.br/wpcontent/uploads/sites/ 47/2013/11/cadmio.pdf. Acesso em mai.2016.

CONSELHO NACIONAL DE MEIO AMBIENTE. Resolução CONAMA n ${ }^{\circ} 3$ de 28 de junho de
1990. Diário Oficial da República Federativa do Brasil, Brasília, 22 de agosto de 1990.

EPA - UNITED STATES ENVIRONMENTAL PROTECTION AGENCY. 2016. Air Monitoring Methods - Criteria Pollutants. Disponível em:

www.epa.gov/ttn/amtic/criteria.html. Acesso em julho, 2016.

FEPAM - Fundação Estadual de Proteção Ambiental Henrique Luís Roessler. Diagnóstico da Qualidade do Ar no Rio Grande do Sul no período de 2003 a 2012 - Porto Alegre: FEPAM, 2014.

Ferraro L.V., Hazenack H. 2000. Clima. In: Vassiliou, M. \& Dick, T (eds.) Carvão e Meio Ambiente. Centro de Ecologia da Universidade Federal do Rio Grande do Sul. Porto Alegre. p.:23-44.

Figueiredo, N.M. 2013 Tratamento de efluente sintético contendo níquel e zinco por biossorção utilizando Sargassum filipendula. Dissertação de Mestrado, Universidade Federal do Rio de Janeiro, Escola de Química, Rio de Janeiro. $86 \mathrm{p}$.

Gajghate, D.G. \& Bhanarkar, A.D. 2005. Characterisation of particulate matter for toxic metals in ambient air of Kochi city, India. Environ. Monit. Assess. 102: 119-129. 
Godoy, M.L., Godoy, J.M., Artaxo, P., 2005. Aerosol source apportionment around a large coal fired power plant- Thermoeletric Complex Jorge Lacerda, Santa Catarina, Brasil, Atm. Environ. 39: 5307-5324.

Hinrichs, R. A. 2009. Energia e Meio Ambiente, $3^{\text {a }}$ ed., Editora Thomson, São Paulo, 708 pp.

IEA Clean Coal Centre- 2012, Trace element emissions from coal. Disponível em: http://www.ieacoal.org.uk/documents/83083/8631/Traceelement-emissions-from-coal . Acesso: $\operatorname{dez} / 2015$.

INSTITUTO BRASILEIRO DE GEOGRAFIA E ESTATÍSTICA. Cidades. Disponível em http://cidades.ibge.gov.br. Acesso: jan/2016.

JAPAN INTERNATIONAL COOPERATION AGENCY (JICA), 1997. The Study on evaluation of environmental quality in regions under influence of coal steam power plants in Federal Republic of Brazil, Final Report, Tokyo, Japan.

Lima A.P. 2007. Um estudo sobre a qualidade do ar em Uberlândia: Material Particulado em Suspensão. Dissertação de Mestrado, Programa de Pós-Graduação em Engenharia Química, Universidade Federal de Uberlândia. 149 pp.

Machado V.B. 2012. Identificação das fontes de MP fino (MP 2,5) de Porto Alegre. Dissertação de Mestrado Instituto de Astronomia, Geofísica e Ciências Atmosféricas Universidade de São Paulo, 144 p.

Maliska, A. M. 2016. Microscopia Eletrônica de Varredura. Disponível em: http://www.usp.br/nanobiodev/wpcontent/uploads/MEV_Apostila.pdf. Acesso: em junho de 2016

Maycon, M., Quitério L.M., Lopes R. Loyolaq J., Arbila G. 2014. Caracterização de metais traço no material particulado atmosférico inferior a 2,5 $\mu \mathrm{m}$ (MP2,5) no entorno de uma área industrial. Rev. Perspec. da Ciência Tec., 6: 212.

Osorio D.M.M., Alves D.D., Rodrigues, Mas, Schuck S. 2015 Morfologia e composição do material particulado atmosférico da bacia hidrográfica do Rio dos Sinos (RS) analisados por microscopia eletrônica de varredura. Rev. Geoch. Brasil. 29(2) 4557.

Paproki, A. 2009. Síntese das zeólitas a partir de cinzas de carvão visando sua utilização na descontaminação de drenagem ácida de mina. Dissertação de Mestrado, Programa de PósGraduação em Engenharia e Tecnologia de Materiais, Pontifícia Universidade Católica do Rio Grande do Sul, 156p.

Pires, M. 1990. Caracterização e modelamento das emissões atmosféricas da usina termelétrica Jacuí I. Dissertação de Mestrado, Programa de Pós-Graduação Engenharia Metalúrgica, Escola de Engenharia, Universidade Federal do Rio Grande do Sul, 207p.
Pires, M., Haidi, F., Teixeira, E. C. 2002. Distribuição geoquímica de elementos traço em carvão, Capítulo 12, In: Meio Ambiente e Carvão: Impactos da exploração e utilização. Teixeira, E.C., Pires, M.J.R., (Eds.). Cadernos de Planejamento e Gestão Ambiental, FEPAM, Porto Alegre. p. 237-252.

Rohde, W.E, G.M., Zwonok, O., Chies, F., 2006. Cinzas de carvão fóssil no Brasil, Aspectos Técnicos e Ambientais, VO1.1, Porto Alegre, CIENTEC, 202p.

Seinfeld, J. H. \& Pandis, S. N. 2006. Atmospheric chemistry and physics: from air pollution to climate change, 2nd ed. John Wiley \& Sons, New York, 1203 pp.

Sundstron, M. 2012. Caracterização e avaliação das cinzas da combustão de carvão mineral geradas na região do Baixo Jacuí - RS. Dissertação de Mestrado, Centro Universitário La Salle, Canoas, $121 \mathrm{p}$.

Vassiliou, M.; Dick, T. (Eds.) 2000. Carvão e Meio Ambiente. Centro de Ecologia UFRGS, Porto Alegre, 479 pp.

WHO Air Quality Guidelines for particulate matter, ozone, nitrogen dioxide and sulfur dioxide global update 2005 disponível: http:// www.euro.who.int/document/E87950.pdf acesso em out.2015. 